\title{
Measure the Level of Low Carbon Economic Development and Analysis of Obstacles Factor in Shandong Province
}

\author{
Qiang Zhao \\ School of Resources and Environment, \\ University of Jinan \\ Jinan, China \\ stu_zhaoq@126.com \\ Xiumei Li \\ School of Resources and Environment, \\ University of Jinan \\ Jinan,China \\ stu lixm@ujn.edu.cn
}

\author{
Qiaoling Guo \\ School of Resources and Environment, \\ University of Jinan \\ Jinan,China \\ 857345869@qq.com
}

\begin{abstract}
The purpose of this study was to obtain lowcarbon economic development level and analyze obstacle factor in Shandong province.This paper first designed the index system of low carbon economic evaluation containing the target layer and system layer and index layer,determined the weight of each index by combining the entropy method and order relationship analysis method, finally used multielement comprehensive evaluation method to measure the level of low carbon economy in Shandong Province. The results show: the level of low carbon economy is a generally upward trend during 2004-2012, comprehensive score has a slightly decline only in 2007 and 2011, it is predicted the level of low carbon economy in the next few years is on the rise. Science and technology system is the main obstructive factor of its development before 2009, but its influence is decreasing now.To scientific development view as guidance, according to the State Situation,combined with the need its economy and social development in Shandong province, steadily promote the development of low carbon economy and realize the sustainable development of economy, making it to become the internal driving force of economic growth.
\end{abstract}

Keywords- handong province; low carbon economy;the index system;obstacles factor;obstacle degree.

\section{INTRODUCTION}

Low carbon economy appears in the late 90's of twentieth Century[1-2]. Now, most scholars believe that low carbon economy is a new economic development model, which its core is based on market mechanism, through the innovation of system, policy and technology, making society to transform for low energy consumption, low emission and high efficiency. The index system of low carbon economy is the foundation of evaluating low carbon economic development, and the basis that it comprehensively reflects its development[3].Therefore, constructing the index evaluation system, evaluating the low carbon economic development level, and studying the influential factors of low carbon economy have important significance extremely.

Based on the domestic and foreign research status[4-5], this study has constructed a set of index evaluation system, which is about low carbon economy, determined the weight of each index by applying combined entropy method and order relationship analysis, measured the level of low carbon economy, reckoned obstacle degree of low carbon economic development and drew the obstacle factor by using multi-element comprehensive evaluation method.

\section{RESEARCH METHOD}

\section{A. The construction of the low carbon economic index system}

Following the basic principles of comprehensiveness, science, maneuverability etc, the index system of low carbon economic evaluation is designed containing the target layer, system layer, index layer[6-7].The target layer is the comprehensive evaluation of low carbon economic development; system layer includes economic system, social system, environment system; index layer include 17 representative indexes, containing per capita GDP, the proportion of the third industry, urban per capita disposable income, the net income of rural residents, the rate of industrial waste water compliance rate, COD emissions harmless etc. the index system low carbon economic evaluation is shown in Table 1 .

\section{B. Evaluation method}

Determination of index weight have more than ten kinds, roughly divided into two categories: objective weighting method and subjective weighting method. Subjective weighting method have analytic hierarchy process, order relationship analysis method, Delphy Law etc[8-10].Objective weighting method have deviation method, principal components analysis, entropy method etc. In order to guarantee the result's credibility, this paper 
firstly used entropy method to calculate the objective weight, and used order relationship analysis method for the subjective weight, then combined the two methods for final weight.

TABLE 1 . The index system of low carbon economic evaluation

\begin{tabular}{|c|c|c|}
\hline Target layer & System layer & Index layer \\
\hline \multirow{14}{*}{$\begin{array}{l}\text { The index } \\
\text { system }\end{array}$} & & per capita GDP \\
\hline & Economic & tertiary industry proportion \\
\hline & system & $\begin{array}{l}\text { available income per person in downtown } \\
\text { rural inhabitant's net income }\end{array}$ \\
\hline & \multirow{4}{*}{$\begin{array}{l}\text { Science and } \\
\text { technology } \\
\text { system }\end{array}$} & $\begin{array}{l}\text { comprehensive utilization rate of industrial } \\
\text { solid waste }\end{array}$ \\
\hline & & $\begin{array}{l}\text { industrial sewage getting up to standard rate } \\
\text { COD emissions }\end{array}$ \\
\hline & & life harmless garbage treatment rate \\
\hline & & population density \\
\hline & \multirow{3}{*}{ Social system } & $\begin{array}{c}\text { housing area of urban population } \\
\text { urbanization rate }\end{array}$ \\
\hline & & urban engel coefficient \\
\hline & & $\begin{array}{l}\text { public steam trams number in every million } \\
\text { people }\end{array}$ \\
\hline & \multirow{4}{*}{$\begin{array}{l}\text { Environment } \\
\text { system }\end{array}$} & $\begin{array}{c}\text { Percentage of green space coverage in } \\
\text { finished area }\end{array}$ \\
\hline & & $\begin{array}{l}\text { industrial pollution governance investment } \\
\text { completed }\end{array}$ \\
\hline & & forest coverage \\
\hline & & carbon dioxide outlet quantity \\
\hline
\end{tabular}

1) Calculate the objective weights by Entropy method

a) Standardize data: Make them dimensionless processing, for unification of different units, as well as convenient for compariso

b) Make index translation: There maybe be zero in some standardized data, so each value plus 1, for conveniently calculating.

c) Calculate the proportion: Suppose there are $n$ evaluated objects and $m$ indexes. Calculate the $i$ proportion of the $j$ object, which used data is shifted.

$$
P_{i j}=\frac{X_{i j}}{\sum_{j=1}^{n} X_{i j}}(i=1,2 \ldots . . m ; j=1,2 \ldots . . n)
$$

d) Calculate entropy: Assuming use the I item entropy.

$$
e_{i}=-\frac{1}{\ln (n)} \sum_{j=1}^{n} P_{i j} \ln P_{i j}\left(e_{i} \geq 0\right)
$$

e) Calculate difference coefficient: The weight represents the influence degree of comprehensive evaluation, which coefficient of weight will increase, with the index difference increasing.

$$
g_{i}=\frac{1-e_{i}}{m-\sum_{i=1}^{m} e_{i}}\left(0 \leq \mathrm{g}_{i} \leq 1\right)
$$

$$
\text { (f) Calculate the weight: } \quad w_{i}=\frac{g_{i}}{\sum_{i=1}^{m} g_{i}}
$$

2) Evaluate the subjective weights by order relationship analysis method

a) To determine the order of important degree. Assume there are $X_{1} X_{2} \ldots \ldots X_{\mathrm{m}}$. The first step is to choose the most important indicators among them, then select the second important index in the rest of the indexes, then continue, and obtain this relationship finally.

$$
X_{1}^{*} \geq X_{2}^{*} \geq \ldots \ldots \geq X_{m}^{*}
$$

b) Look for two data, then draw a ratio of importance degree.

$$
w_{k-1} / w_{k}=r_{k}(k=m, m-1 \ldots . .3,2)
$$

3) Determinate the final weight:Assume that have $m$ objects of evaluation, $n$ indexes of evaluation, to determine the objective weight by using the entropy method.

$$
w_{1}=\left(w_{1}^{(1)}, w_{2}^{(1)}, \ldots, w_{m}^{(1)}\right)
$$

Calculate the subjective weight by using order relationship method.

$$
w_{2}=\left(w_{1}^{(2)}, w_{2}^{(2)}, \ldots, w_{m}^{(2)}\right)
$$

Calculate the weight of Priority combination. 


$$
w_{0}=\left(w_{1}^{(0)}, w_{2}^{(0)}, \ldots, w_{m}^{(0)}\right)
$$

For the $i$ object, calculate the comprehensive score; in order to get the optimal weights, choose the weight to

$$
\min H(\mathrm{w})=\sum_{i=1}^{m} \sum_{j=1}^{n}\left\{\begin{array}{l}
{\left[\left(w_{1}-w_{0}\right) \times X_{i j}\right]^{2}+} \\
{\left[\left(w_{2}-w_{0}\right) \times X_{i j}\right]^{2}}
\end{array}\right\}
$$

(10)

Obtain the results by using Lagrange.

$$
w=A^{-1} \times\left[B+\frac{1-e^{T} A^{-1} B}{e^{T} A^{-1} e} \times e\right]
$$

Among the: $A=\operatorname{diag}\left[\sum_{j=1}^{n} X_{1 j}^{2}, \sum_{j=1}^{n} X_{2 j}^{2}, \ldots, \sum_{j=1}^{n} X_{m j}^{2},\right]$ $\mathrm{e}=[1,1, \ldots, 1]^{T}$

$B=\left[\begin{array}{l}\sum_{j=1}^{\mathrm{n}} \frac{1}{2}\left(w_{1}+w_{2}\right) \times X_{1 j}^{2}, \sum_{j=1}^{n} \frac{1}{2}\left(w_{1}+w_{2}\right) \times X_{2 j}^{2}, \ldots, \\ \sum_{j=1}^{n} \frac{1}{2}\left(w_{1}+w_{2}\right) \times X_{m j}^{2}\end{array}\right]$

The formula include subjective factors and objective factors, for making result more comprehensive and accurate。

4) Calculate obstacle factors

a) Calculate contribution rate of single factor. The contribution rate of single factor represent influence on the overall objects, that is the size of weight, denoted by $F_{j}$.

b) Calculate index's deviation degree. Deviation degree represents the gap, apart form the expected goal of low carbon economic development, the formula is: $D_{\mathrm{j}}=1-X_{i j}^{*}$.

c) Calculate obstacle degree of index in standard layer, the formula for calculating is:

$$
O_{\mathrm{j}}=\frac{F_{j} \times D_{j}}{\sum_{j=1}^{n} F_{j} \times D_{j}} \times 100 \% .
$$

d) Calculate obstacle degree of index in standard layer. Obstacle degree in criterion layer represents the influence degree of the criterion layer indicators on the overall goals. the formula for calculating is: $M_{i}=\sum O_{j}$

\section{MEASURE THE LEVEL OF LOW CARBON ECONOMIC DEVELOPMENT}

\section{A. Calculate the index weight}

1) Calculate the objective weight by entropy method: We referred the related data of 17 indexes, through Urban Statistical Yearbook in Shandong Province, China Urban Statistical Yearbook and website of China Statistics calculate that can making deviation of subjective evaluation score be minimum. A formula is satisfied.

Bureau from 2004 to 2012. Then make date processing standardization by using entropy method. The results are shown in Table 2.

Next, make all index translation, each value plus 1 , and use the formula to calculate the weight. The results are as follows:

$W_{1}=(0.043,0.059,0.061,0.083,0.081,0.044,0.057$, $0.069,0.050,0.061,0.054,0.048,0.063,0.053,0.054$, $0.062,0.058)$

2) Evaluate the subjective weights by order relation analysis method: Obtain the subjective weight by the formula of order relationship analysis:

$W_{2}=(0.013,0.152,0.01,0.121,0.132,0.031,0.02,0.063$, $0.048,0.021,0.021,0.025,0.063,0.076,0.056,0.034$, $0.214)$

3)Determinate the final weight: Make weight, which is obtained by the above two, calculate the final by using formula. The final results are as follows:

$W=(0.038,0.098,0.041,0.044,0.103,0.033,0.045$, $0.071,0.050,0.036,0.026,0.039,0.057,0.071,0.048$, $0.050,0.15$ )

\section{B. Calculate obstacle factors}

Calculate the various indicator's obstacle degree from 2004 to 2012, and obtain obstacle degree of the system layer, the results are shown in Fig. 1.

Fig. 1 shows: The science and technology system is the main obstructive factor of low carbon economy before 2009 , and the influence of its obstacle degree is the downward trend since 2004; it is predicted that the trend will keep on in the next few years. Obstacle degree of the economic system is also on the decline at a rapid speed; it is predicted the trend will keep on in the next few years, too. Obstacle degree of the environmental system has risen in small range, and there are rising trend in the next few years. Social system is the most unstable of the four systems, which shows that municipal problems are the main crux, such as the high-speed-growing population, urban planning etc.

\section{Evaluation of low carbon economy development of Shandong Province}

Use membership function to calculate the 17 indexes in this evaluation, containing positive index and negative index, the calculation formula follows:

Positive index: $\mu(x)=\left\{\begin{array}{l}1 \\ \frac{f(x)-\inf (f)}{\sup (f)-\inf (f)} \\ 0\end{array}\right.$

Negative index: $\mu(x)=\left\{\begin{array}{l}1 \\ \frac{\sup (f)-f(x)}{\sup (f)-\inf (f)} \\ 0\end{array}\right.$ 
Bring the 17 index into above two formulas, thus $0.267,0.023,0,0.098,0.012,0,0.254,0,0.076,0,0)$ obtain the evaluation vector: $\mathrm{R} 1=(0,0.123,0,0,0,0$,

TABLE 2. Dimensionless indexes

\begin{tabular}{|c|c|c|c|c|c|c|c|c|c|}
\hline concrete targets & 2004 & 2005 & 2006 & 2007 & 2008 & 2009 & 2010 & 2011 & 2012 \\
\hline per capita GDP & 0 & 0.099 & 0.203 & 0.316 & 0.467 & 0.551 & 0.698 & 0.875 & 1 \\
\hline $\begin{array}{l}\text { tertiary Industry } \\
\text { Proportion }\end{array}$ & 0 & 0.067 & 0.159 & 0.253 & 0.369 & 0.459 & 0.629 & 0.828 & 1 \\
\hline $\begin{array}{l}\text { available income per } \\
\text { person in Downtown }\end{array}$ & 0 & 0.080 & 0.168 & 0.295 & 0.420 & 0.513 & 0.643 & 0.818 & 1 \\
\hline $\begin{array}{l}\text { rural inhabitant's net } \\
\text { income }\end{array}$ & 0 & 0.071 & 0.144 & 0.250 & 0.359 & 0.439 & 0.586 & 0.814 & 1 \\
\hline $\begin{array}{c}\text { Comprehensive } \\
\text { utilization rate of } \\
\text { industrial solid waste }\end{array}$ & 0 & 0.519 & 0.933 & 0.420 & 1 & 0.656 & 0.371 & 0.414 & 0.329 \\
\hline $\begin{array}{l}\text { industrial sewage } \\
\text { getting up to standard } \\
\text { rate }\end{array}$ & 0 & 0.539 & 0.410 & 0.836 & 1 & 0.776 & 0.697 & 0.697 & 0.899 \\
\hline COD emissions & 0.884 & 0.890 & 0.899 & 0.927 & 0.957 & 0.980 & 1 & 0 & 0.045 \\
\hline $\begin{array}{l}\text { Life harmless garbage } \\
\text { treatment rate }\end{array}$ & 0.696 & 0 & 0.298 & 0.563 & 0.531 & 0.809 & 0.844 & 0.859 & 1 \\
\hline population density & 1 & 0.903 & 0.806 & 0.677 & 0.580 & 0.451 & 0.225 & 0.129 & 0 \\
\hline $\begin{array}{l}\text { housing area of urban } \\
\text { population }\end{array}$ & 1 & 0.702 & 0.588 & 0.516 & 0.299 & 0.232 & 0.191 & 0.036 & 0 \\
\hline urbanization rate & 1 & 0.894 & 0.858 & 0.764 & 0.588 & 0.541 & 0.341 & 0,188 & 0 \\
\hline $\begin{array}{l}\text { Urban Engel } \\
\text { coefficient }\end{array}$ & 0 & 0.653 & 0 & 0.346 & 0.615 & 0.661 & 0.638 & 0.950 & 1 \\
\hline $\begin{array}{l}\text { in every million people } \\
\text { public steam trams } \\
\text { number }\end{array}$ & 0 & 0.182 & 0.683 & 0.812 & 0.920 & 0.661 & 0.638 & 0.950 & 1 \\
\hline $\begin{array}{l}\text { forest coverage rate of } \\
\text { finished area }\end{array}$ & 0 & 0.111 & 0.269 & 0.444 & 0.634 & 0.857 & 0.904 & 0.904 & 1 \\
\hline $\begin{array}{c}\text { industrial pollution } \\
\text { governance investment } \\
\text { completed }\end{array}$ & 0 & 0.458 & 0.439 & 0.613 & 1 & 0.256 & 0.122 & 0.502 & 0.607 \\
\hline forest coverage & 0 & 0 & 0 & 0 & 0 & 1 & 1 & 1 & 1 \\
\hline $\begin{array}{l}\text { carbon dioxide outlet } \\
\text { quantity }\end{array}$ & 1 & 0.714 & 0.627 & 0.446 & 0.401 & 0.205 & 0.188 & 0.107 & 0 \\
\hline
\end{tabular}

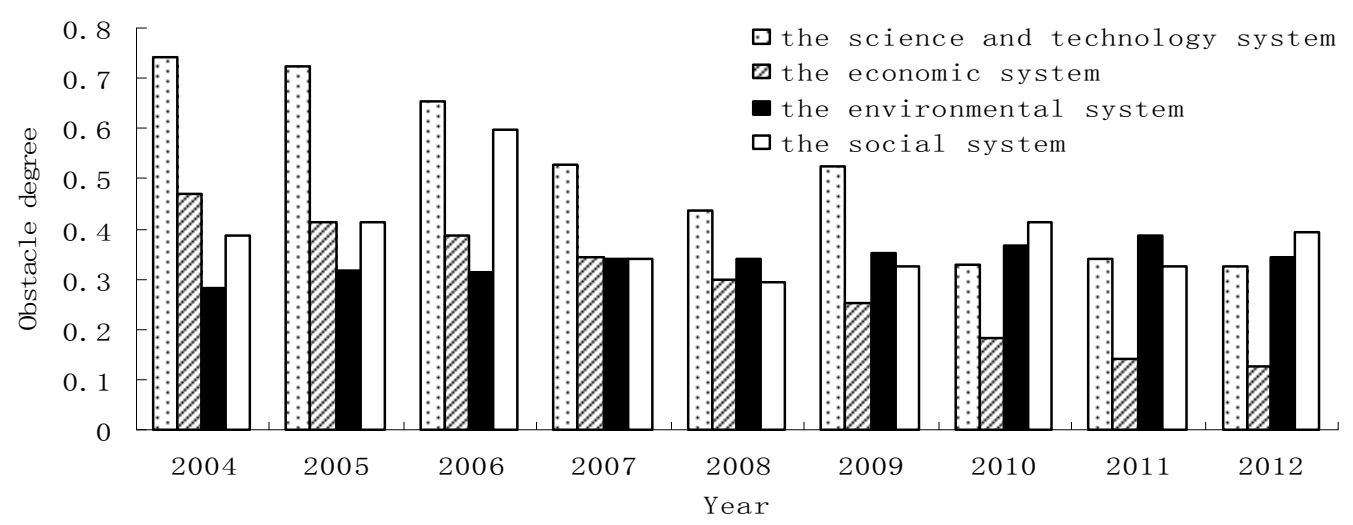

Figure 1. Past years the broken line chart of obstacle degree 
Use the same method separately to calculate R2, R3,.. $\mathrm{R} 12$, finally calculate the comprehensive score of low carbon economy in Shandong province from 2004 to 2012 , by using multi-element comprehensive evaluation method. the results are shown in Fig.2

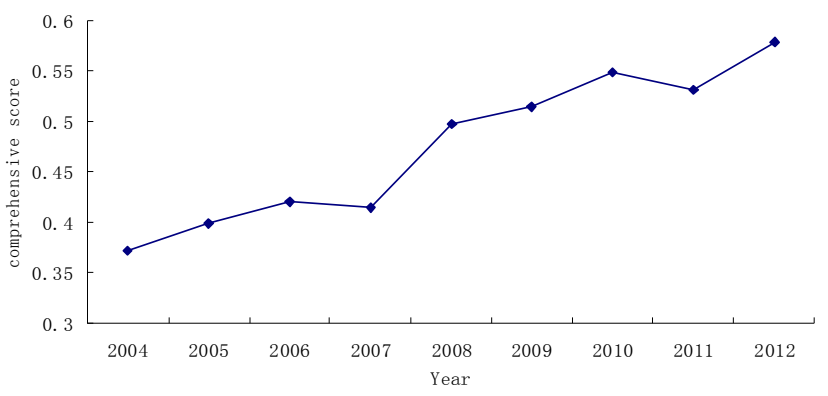

Figure 2. The comprehensive score of low carbon economy from 2004 to 2012 in Shandong Province

Fig. 2 shows: the trend is a rising trend generally from 2004 to 2012, the comprehensive score has small decline only in 2007 and 2011 and there is a rising trend significantly in other years. Conclude that the development of low carbon economy in Shandong province is on the rise in the next few years. In addition, the comprehensive score of low carbon economy increased slower from 2004 to 2012, just 0.206.

\section{CONCLUSION}

This paper established the index system of low carbon economic evaluation in Shandong province, and used the contained entropy method and order relationship analysis method to determine the weight of each index, and finally measured the development level of low carbon economy by multi-element comprehensive evaluation method.

In Shandong Province, low carbon economy is overall upward trend during 2004-2012, and comprehensive score has small decline only in 2007 and 2011. It is predicted that the development of low carbon economy for the next few years is on the rise. At the same time, there are some shortages in the development of low carbon economy, such as low carbon economy comprehensive score only grew by 0.206 during 20042012, which the development rate of low carbon economy is slower in Shandong Province.

Science and technology system is the main obstructive factors of low carbon economy before 2009, Which predicts the trend is declining in the next few years.

\section{ACKNOWLEDGEMENTS}

The research work was supported by Natural Science Foundation of China under Grant No. 41471160 and Natural Science Foundation of Shandong Provincial under Grant No. ZR2013DL001 and Science Foundation of University of Jinan under Grant No. XKY1310.

\section{REFERENCES}

[1] Luis Mundaca T., Anil Markandya, Jørgen Nørgaard," Walking away from a low-carbon economy? Recent and historical trends using a regional decomposition analysis,"Energy Policy, Volume 61, Oct. 2013, PP 1471-1480,doi:10.1016/j.enpol.2013.04.083

[2] Shen Jianfei, Xue Song, Zeng Ming, Wang Yi, Wang Yuejin, Liu Xiaoli," Low-carbon development strategies for the top five power generation groups during China's 12th Five-Year Plan period,'Renewable and Sustainable Energy Reviews, Volume 34, June 2014, PP 350-360,doi:10.1016/j.rser.2014.03.029

[3] Xiangsheng Dou' “ Low Carbon-Economy Development: China's Pattern and Policy Selection,'Energy Policy,Volume 63, Dec 2013, PP 1013-1020,doi:10.1016/j.enpol.2013.08.089

[4] Zhaoguang $\mathrm{Hu}$, Jiahai Yuan, Zheng Hu' "Study on China's low carbon development in an Economy-Energy-ElectricityEnvironment framework,"Energy Policy, Volume 39, May 2011, PP 2596-2605,doi:10.1016/j.enpol.2011.02.028

[5] Junsong Jia, Ying Fan, Xiaodan Guo, "The low carbon development (LCD) levels' evaluation of the world's 47 countries (areas) by combining the FAHP with the TOPSIS method," Expert Systems with Applications: Volume 39,1 June 2012, PP 66286640,doi:10.1016/j.eswa.2011.12.039

[6] Anne Zimmer, Michael Jakob, Jan Christoph Steckel, "What motivates Vietnam to strive for a low-carbon economy? - On the drivers of climate policy in a developing country,"Energy for Sustainable Development,Volume 24, February 2015, PP 1932,doi:10.1016/j.esd.2014.10.003

[7] Nannan Wang, Yen-Chiang Chang,'The evolution of low-carbon development strategies in China,"Energy,Volume 68, 15 April 2014, PP 61-70,doi:10.1016/j.energy.2014.01.060

[8] Nannan Wang, Yen-Chiang Chang "The development of policy instruments in supporting low-carbon governance in China," Renewable and Sustainable Energy Reviews ,Volume 35, July 2014, PP 126-135,doi:10.1016/j.rser.2014.03.021

[9] Zhou-Jing Wang' "Uncertainty index based consistency measurement and priority generation with interval probabilities in the analytic hierarchy process",in Press

[10] Yong Tang, Honghang Sun, Qiang Yao, Yibo Wang," The selection of key technologies by the silicon photovoltaic industry based on the Delphi method and AHP (analytic hierarchy process): Case study of China,"Energy,Volume 75,Oct. 2014, PP 474482, doi:10.1016/j.energy.2014.08.003 